\title{
Laser Treatment of Retinal Angiomatosis
}

\author{
CAROL M. LANE, GEORGE TURNER, ZDENEK J. GREGOR, ALAN C. BIRD \\ London
}

\begin{abstract}
Summary
We have treated 26 retinal angiomas of less than $4.5 \mathrm{~mm}$ in size in 15 eyes using repeated applications of contiguous argon blue green laser burns. All except one of the angiomas regressed without a massive exudative response of treatment. Haemorrhage occurred in two cases but only affected the visual outcome in one eye. Traction retinal detachment persisted in $50 \%$ of the large angiomas, despite regression of the tumour.
\end{abstract}

Angiomatosis retinae as described by von Hippel $^{1}$ was subsequently linked to systemic disease by Lindau ${ }^{2}$ and classified as one of the phakomatoses by van der Hoeve in his Doyne Memorial lecture of $1932 .^{3}$ The mode of inheritance is autosomal dominant with variable expression, and a gene defect has now been localised on chromosome $3 .{ }^{4}$ The angiomas appear as fleshy pink nodules and consist of a meshwork of large capillaries with continuous endothelium, basement membrane and pericytes with intervascular stromal cells containing glycogen granules, ${ }^{5,6}$

Retinal angiomas have been documented to appear and to enlarge progressively. ${ }^{7}$ The prognosis for untreated angiomas is very poor $^{8}$ and only rarely do they regress spontaneously. ${ }^{6}$ There is so much variation in the size, growth rate and associated ocular features of angiomas at presentation that analysis of the success of various forms of treatment in small numbers of patients has proved difficult. Irradiation was recommended early in this century and further studies are now in progress. Penetrating diathermy, ${ }^{9}$ xenon photocoagulation and later cryotherapy were used in some series $^{10,11}$ but massive exudation and a $71 \%$ incidence of haemorrhage have been reported. ${ }^{11}$ In order to reduce these complications of treatment repeated 'gentle' triple freeze cryotherapy has been advocated for larger tumours. ${ }^{12}$ For the same reason Wessing ${ }^{13}$ suggested the use of multiple treatments using low intensity xenon photocoagulation.

Argon blue/green laser photocoagulation has the theoretical advantages of out-patient treatment with low intensity burns that could reduce the incidence of complications. ${ }^{11}$ There are few published reports of its use, ${ }^{11,14}$ but Goldberg ${ }^{14}$ reported treatment of the feeder vessels and of the angioma itself. Although this appeared to be effective for lesions of less than $0.8 \mathrm{~mm}$ diameter, histopathological examination revealed small amounts of residual angiomatous tissue in one treated lesion. ${ }^{15}$ The role of the laser treatment, particularly in the management of large angiomas, has not been clarified to date. In order to define the potential value of argon laser photocoagulation in the treatment of retinal angiomas we carried out a prospective study in which laser was the only method of treatment

\section{Patients and methods}

Twelve patients ( 6 male, 6 female), median age 24 years, with 26 untreated retinal angiomata of $4.5 \mathrm{~mm}$ or less in size which did not involve the optic disc ora serrata, were given a standardised form of laser treatment. 
Eight presented with blurred vision, two with floaters, one with field loss and one at followup after treatment of the other eye.

A method of staging retinal angiomata was originally suggested by $\mathrm{Vail}^{9}$ and Duke Elder, ${ }^{16}$ and modified by Welch. ${ }^{17}$ We have frequently observed fibrovascular proliferation over the surface of untreated angiomas, as reported by Nicholson ${ }^{18}$ and Gass. ${ }^{19}$ To include this phenomenon we modified the existing classification as follows:

Grade 1: simple angioma without vessel dilation

Grade 2: $1+$ feeder vessel dilation $+/-$ intra-retinal exudates

Grade 3: 2 + serous retinal detachment

Grade $4: 2 / 3+$ proliferative vitreoretiopathy, causing rhegmatogenous or traction retinal detachment

The presenting angiomas were composed of 14 small $(<1.5 \mathrm{~mm})$ and 12 large $(1.5 \mathrm{~mm}$ $4.5 \mathrm{~mm}$ ) lesions of Grades 1 to 4 (Table I). Four of the patients with Grade 4 angiomas had associated retinal detachment of more than one third of the retina and two had diabetes. Each angioma was treated with repeated applications of argon blue green laser burns, sufficient to blanch the surface, which were performed at 1-2 weekly intervals (Fig. 1). The median spot size was $200 \mu \mathrm{m}$ (range $100-1000 \mu \mathrm{m}$ ) at median power $0.5 \mathrm{~W}$ (range 0.1-1.6W) for 0.2 seconds (range $0.09-1.0$ seconds). Uptake of laser light was potentiated by intravenous injection of $1-2 \mathrm{ml}$ of $20 \%$ sodium fluorescein in some cases, particularly where there was marked whitening of the surface of the angioma which prevented any visible surface photocoagulation effect. Local anaesthesia to the ocular surface, with oral analgesia in a few patients, proved sufficient and retrobulbar anaesthesia was not required.

The treatment series was considered complete when the feeder vessels narrowed to their normal size with whitening and shrinkage of the angioma and resolution of retinal exudates if these were present (Fig. 2). Fluorescein angiography was performed to confirm the absence of residual tumour.

\section{Results}

All 14 small angiomata of Grades 1 and 2 regressed without complications (Fig. 3). Regression was achieved in 1-6 sessions (median one using 7-469 burns (median 34) with follow-up of 1 to 13 months (median 8 months). All but one of the 12 large angiomata regressed, but required more laser treatment than small angiomata: a range of 2-18 sessions (median 7) using 145-2763 burns (median 873) with follow-up of between 4 and 136 months (median 27.5 months). In some lesions very little initial response was seen, the first effects of treatment only being detectable as discontinuity of the capillary bed of fluorescein angiography. Shrinkage of large lesions with narrowing of the vessels was frequently delayed and it was typical for these changes to become suddenly apparent near the end of

PRE-TREATMENT GRADE

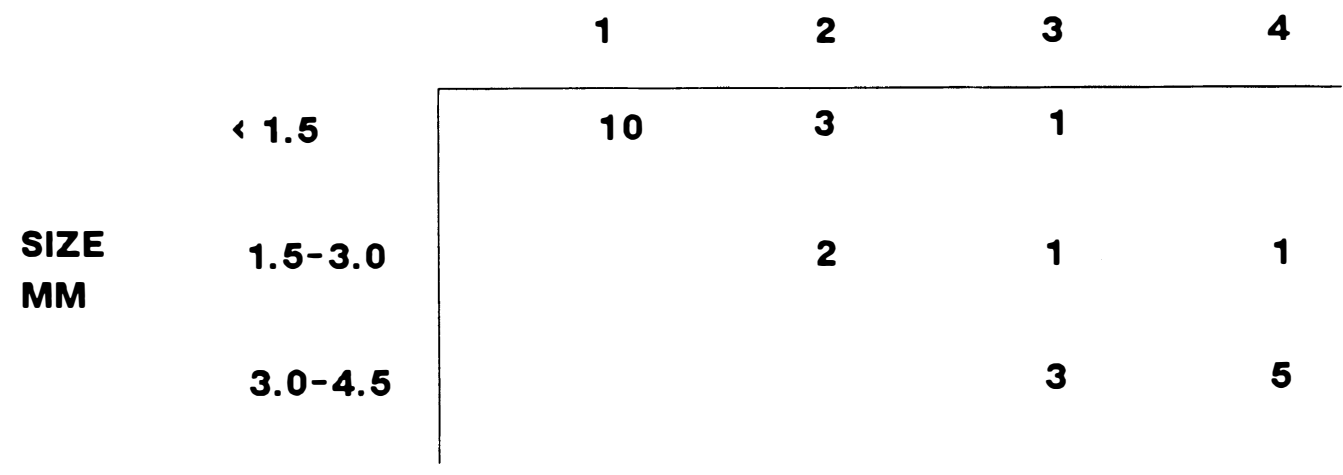

Table1 Grading of angiomas in relation to size $(\mathrm{mm})$ 
the treatment series.

Both Grade 2 large angiomata regressed without complications of treatment and all but one Grade 3 large angiomata, together with Grade 4 angioma, regressed with complete resorption of subretinal fluid. In the remaining five Grade 4 angiomata, which all regressed, total resorption of sub-retinal fluid was prevented by proliferative vitroretinopathy. In three of these a localised traction retinal detachment remained and did not affect the fovea, but in one case an epiretinal

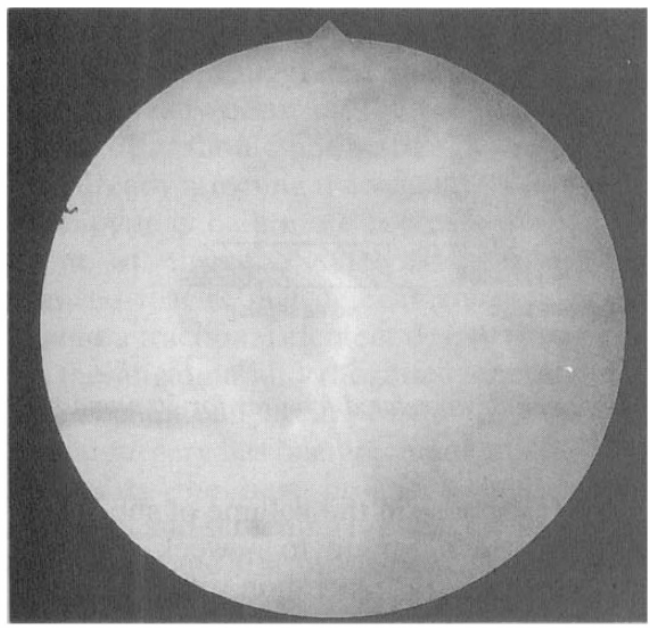

a

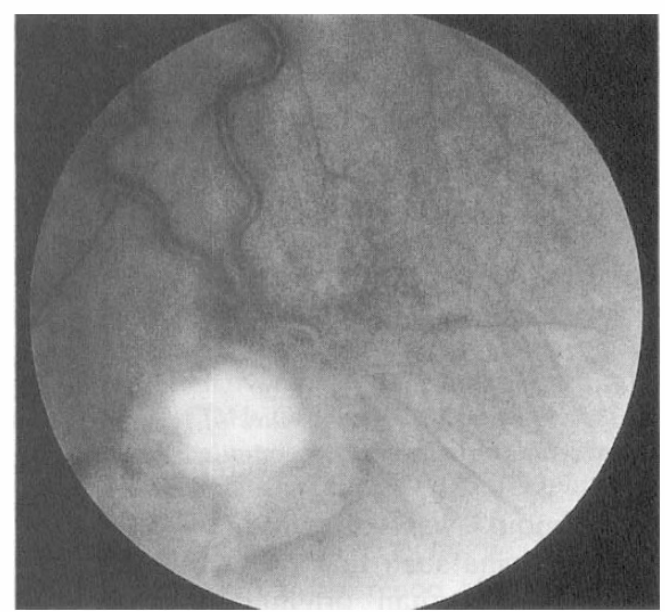

b

Fig. 1. (a) Grade 4 angioma before treatment, showing dilated feeder vessels and serous retinal detachment. (b) The same angioma immediately after treatment, showing blanched spots at the sites of laser burns. membrane caused distortion of the macula. In the fifth the retina became totally detached during treatment (Stage $4 \mathrm{c}$ of massive periretinal proliferation). ${ }^{20}$

It was not unusual to see new angiomas appear or grow in the region of the treated angioma, so particular vigilance was required during a course of treatment to the initial lesion. Complete failure of regression occurred with only one large Grade 3 angioma which had produced massive exudation before presentation; it is likely that part of
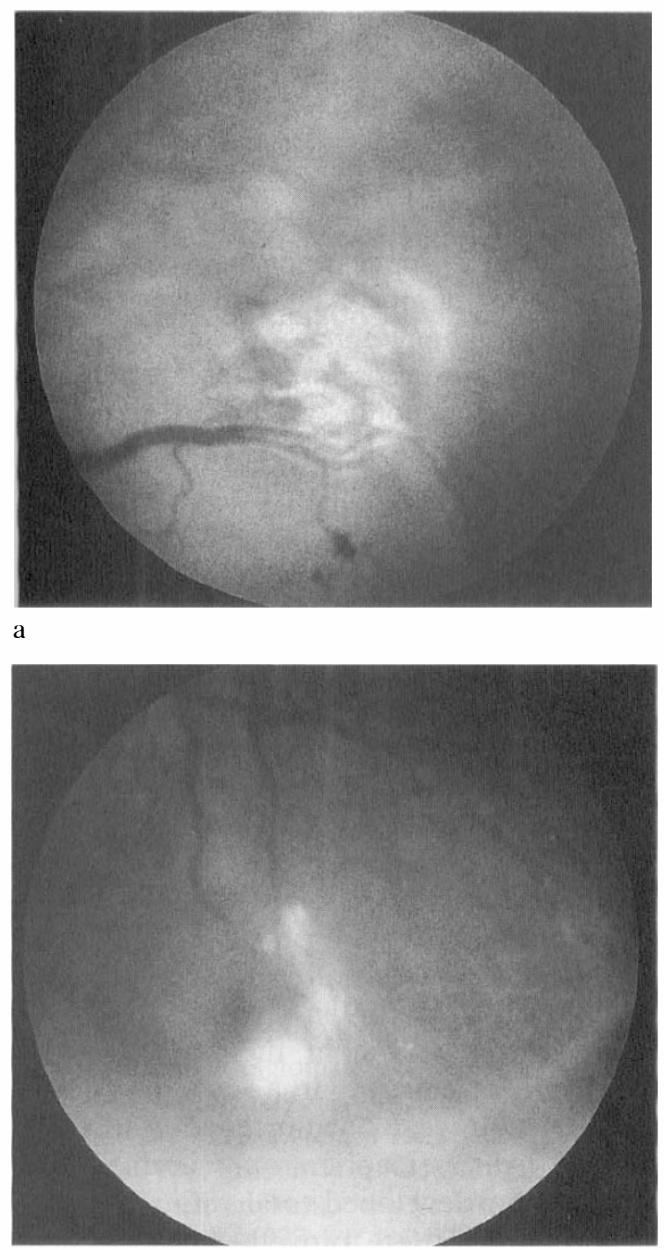

b

Fig. 2. (a) Grade 3 angioma before treatment, showing dilated feeder vessels and serous retinal detachment. (b) The same angioma showing regression after treatment, with scarring and shrinkage of the angioma, narrowing of the feeder vessels to normal calibre and retinal reattachment. 


\section{RESPONSE OF ANGIOMAS TO TREATMENT}

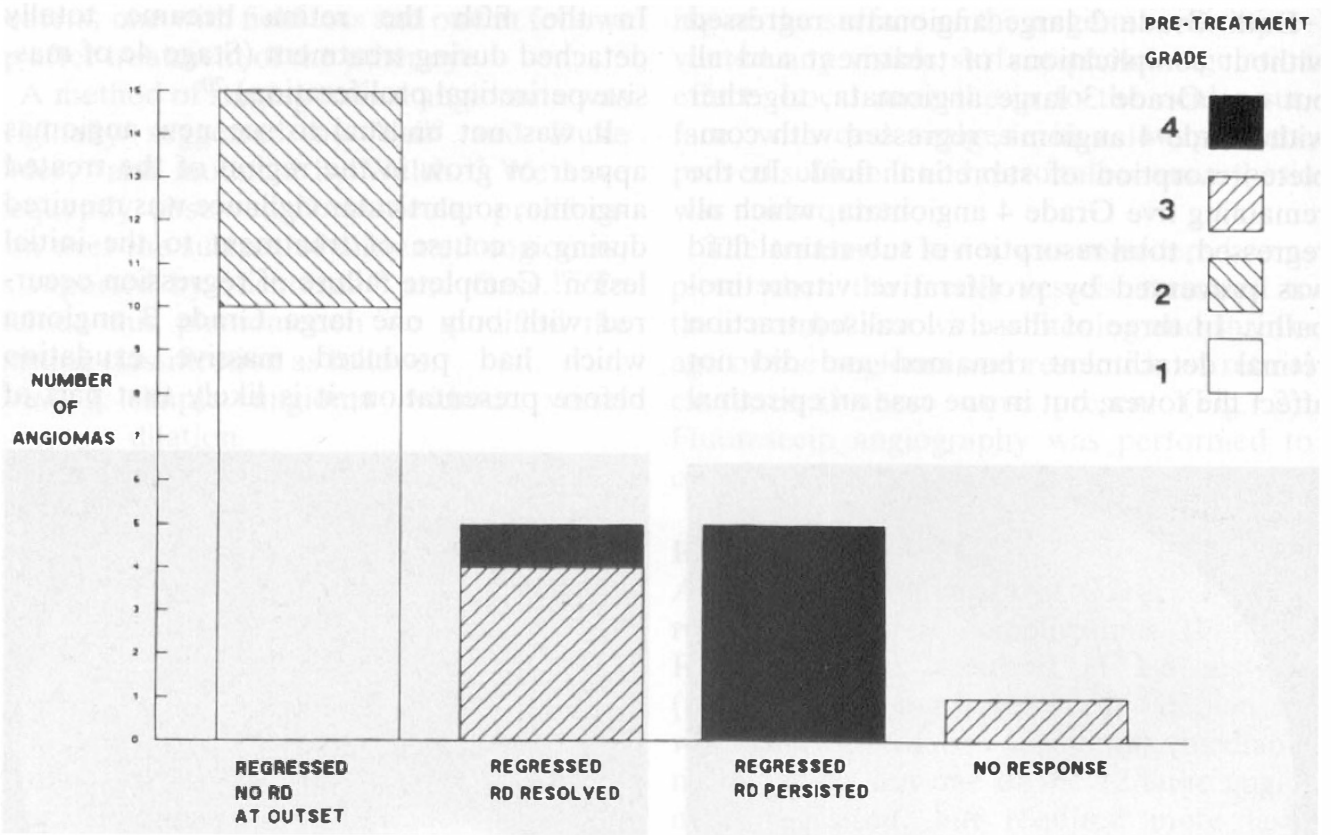

Fig. 3. Histogram showing rates of regression and the outcome of associated features for 26 angiomata treated with argon laser photocoagulation.

the tumour was obscured by detached opaque retina such that the actual size was much greater than originally thought. In addition new angiomatous tissue appeared adjacent to a regressed angioma in two patients after 8 months and 10 years follow up.

Treatment of all small angiomas and half of the large angiomas did not affect the visual acuity. An improvment in visual acuity was associated with resorption of sub-retinal fluid at the macula in three patients. The visual acuity deteriorated in three cases with Grade 4 angiomas: $6 / 6$ to $6 / 9$ in the patient with an epiretinal membrane at the macula, from $6 / 18$ to finger counting in a second who suffered a sub-foveal haemorrhage, and from $6 / 36$ to light perception only in the third patient who developed total retinal detachment. The latter proved unsalvageable despite closed intra-ocular microsurgery.

Repeated laser treatment did not produce retinal detachment de novo and was not associated with a massive exudative response, as previously described. ${ }^{11}$ In patients with pre-existing retinal detachment a minor increase in the volume of sub-retinal fluid was seen for up to a week following treatment. With resolution of the retinal detachment and retinal oedema retinal exudates appeared, only to resolve within a few months. Subretinal haemorrhage occurred in two but only affected the visual acuity in the case where it spread to below the fovea.

\section{Discussion}

The results of this prospective series show that repeated applications of a contiguous grid of laser photocoagulation over the surface of retinal angiomata produced effective regression. Successful treatment was achieved in angiomas of up to $4.5 \mathrm{~mm}$ in diameter, even in the presence of exudative retinal detachments involving up to half the retina. These large angiomas could be treated without an increase in the retinal detachment or haemorrhage, except in two cases, and a massive exudative response was avoided. One problem in comparing these results with previous series of large angiomata is that the effects of angiomata are the same as the complications of therapy. Never- 
theless the low rate of haemorrhage and of retinal detachment following laser treatment appears different from the results recorded by others. ${ }^{11}$

Laser treatment, although time-consuming, was easily performed in the outpatient clinic. Admittedly there are limitations to this form of therapy. We have not assessed the effectiveness of laser treatment for tumours of greater than $4.5 \mathrm{~mm}$ diameter. In such cases an adjunct to laser treatment, such as cryotherapy ${ }^{12}$ or radiotherapy ${ }^{21}$ may be necessary. Angiomas on the optic disc were not included for fear of visual loss. For this reason Gass $^{22}$ suggested that these lesions, which usually occur on the temporal margin of the disc, should not be treated unless they are already affecting the visual acuity. Radiotherapy may be a more useful form of treatment at this particular site. Our series showed that retinal detachment may persist due to a tractional element despite regression of the angioma and rhegmatogenous retinal detachment can occur. In this case conventional surgery has been recommended. ${ }^{23}$

Clearly the best prognosis is for small tumours and screening is essential if these are to be detected. In this respect it is important to recognise that in von Hippel-Lindau disease retinal angiomas are the most common presenting symptoms or sign. 8,22 They have been discovered as early as five years of age ${ }^{8}$ and Huson ${ }^{2+}$ proposed a protocol for screening all patients at risk, which involves annual clinical assessment with retinal examination from the age of five years. Fluorescein angiotherapy is valuable for detecting early lesions and we perform annual fluorescein angiotherapy, in addition to ophthalmoscopy, in patients with a definite history of retinal angiomatosis. Such a protocol should ensure that only small angiomas require treatment. Furthermore, if a patient, who has not been screened previously presents with a large angioma, is treated and kept under regular review, only small angiomas will require therapy thereafter. Because of the early ocular presentation of the disease, it is frequently the ophthalmologist who instigates general assessment of the patient. The screening should involve urinary VMA and metadrenaline estimation to exclude phaeo- chromocytoma from the age of 10 years and biennial cranial CT or NMR scan, to look for cerebellar haemangioblastoma from the age of 15 years. Biennial abdominal CT scan of the kidneys to exclude renal carcinoma, adrenals and pancreas is suggested from the age of 20 years. ${ }^{8}$

\section{References}

${ }^{1}$ von Hippel: E Über eine sehr seltene erkrankung der netzhaut. Arch f. Ophthalmol 1904; 59: 83-106.

${ }^{2}$ Lindau A: Zür frage der angiomatosis retinae und ihrer hirnkompkationen. Acta Ophthalmol 1927; 4: 193-226.

${ }^{3}$ van der Hoeve J: Eye symptoms in phakomatoses (The Doyne Memorial Lecture). Trans Ophthalmol Soc UK 1932; 52: 380-410.

${ }^{4}$ Seizinger BR, Rouleau GA, Ozelius LJ et al: von Hippel-Lindau disease maps to the region of chromosome 3 associated with renal cell carcinoma. Nature 1988: 332: 268-9.

${ }^{5}$ Nicholson DH, Green WR, Kenyon KR: Light and electron microscopic study of early lesions in angiomatosis retinae. Am J Ophthalmol 1976; 82: 1.93-204.

${ }^{6}$ Whitson JT, Welch RB, Green R: von HippelLindau disease: case report of a patient with spontaneous regression of a retinal angioma. Retina 1986; 6: 253-9.

7 Jesberg JO, Spencer WH, Hoyt WF. Incipient lesions of von Hippel-Lindau disease. Arch Ophthalmol 1980; 80: 632-40.

${ }^{8}$ Hardwig P, Robertson DM: von Hippel-Lindau disease: a familial, often lethal, multi-system phakomatosis. Ophthalmology 1984; 91: 26370.

${ }^{9}$ Vail D: Angiomatosis retinae, eleven years after diathermy coagulation. Am J Ophthalmol 1958; 46: 525-34.

${ }^{10}$ Holmes Sellors PJ, Archer D: The management of retinal angiomatosis. Trans Ophthalmol Soc UK 1969; 89: 529-43.

${ }^{11}$ Annesley WH, Leonard BC, Shields JA, Tasman WS: Fifteen year review of treated cases of retinal angiomatosis. Trans Am Soc Otol Ophthalmol 1977; 83: 446-53.

12 Sigelman J: Angiomatosis Retinae: chapter 12 in Retinal diseases. Pathogenesis, laser therapy and surgery. Little, Brown \& Co. Boston/Toronto 1984: 311-30.

${ }_{13}$ Wessing A: 10 jahre lichtkoagulation bei angiomatosis retinae. Klin $\mathrm{Mbl}$ Augenheilk 1967; 150: $57-71$. 
${ }^{14}$ Goldberg MF, Koenig S: Argon laser treatment of von Hippel-Lindau retinal angiomas I. Clinical and angiographic findings. Arch Ophthalmol 1974; 92: 121-5.

${ }^{15}$ Apple DJ, Goldberg MF, Wyhinny GJ: Argon laser treatment of von Hippel-Lindau retinal angiomas II. Histopathology of treated lesions. Arch Ophthalmol 1974; 92: 126-30.

${ }^{16}$ Duke-Elder S: System of ophthalmology Vol. 10. Diseases of the retina. C. V. Mosby Co., St Louis 1967; 738-54.

17 Welch RB: von Hippel-Lindau disease: the recognition and treatment of early angiomatosis retinae and the use of cryotherapy as an adjunct to surgery. Trans Ophthalmol Soc 1970; 68: 367-424.

${ }^{18}$ Nicholson DH, Green WR: Vascular tumours of the retina and optic nerve. Chapter 5 in Paediatric ocular tumours, Masson Publishing USA Inc 1981: 65-73.

${ }^{19}$ Gass, JDM: Angiomatosis retinae (von Hippel's disease). Chapter 10 in Differential diagnosis of intraocular tumours. A stereoscopic presentation. C.V. Mosby Co., St Louis 1974.

${ }^{20}$ Machemer R: Pathogenesis and classification of massive periretinal proliferation. $\mathrm{Br} J$ Ophthalmol 1978; 62: 737-47.

${ }^{21}$ Plowman PN, Harnett AN: Radiotherapy in benign orbital disease. I: Complicated ocular angiomas. Br J Ophthalmol 1988; 72: 286-8.

${ }^{22}$ Gass JD, Braunstein R: Sessile and exophytic capillary angiomas of the juxtapapillary retina and optic nerve head. Arch Ophthmol 1980; 98: $1790-7$.

${ }^{23}$ Nicholson DH, Anderson LS, Blodi C: Rhegmatogenous retinal detachment in angiomatosis retinae. Am J Ophthalmol 1986; 101: $187-9$.

${ }^{24}$ Huson SM, Harper PS, Hourihan MD, Cole G, Weeks RD, Compston DAS: Cerebellar haemangioblastoma and von Hippel-Lindau disease. Brain 1986; 109: 1297-310. 